\title{
Prevalence of dysglycaemic events among inpatients with diabetes mellitus: a Singaporean perspective
}

\author{
Kheng Yong $\underline{\text { Ong }}{ }^{1,2}$, BSc(Hons), Yu Heng $\underline{K w a n}^{1,4}$, BSc(Hons), Hooi Ching $\underline{\text { Tay }}{ }^{3}$, BSc(Hons), Doreen Su-Yin $\underline{T_{a n}}{ }^{3}$, PharmD, \\ Joanne Yeh Chang $^{1}$, PharmD
}

INTRODUCTION As the effectiveness of intensive glycaemic control is unclear and recommended glycaemic targets are inconsistent, this study aimed to ascertain the prevalence of dysglycaemia among hospitalised patients with diabetes mellitus in an Asian population and evaluate the current standards of inpatient glycaemic control.

METHODS A retrospective observational study was conducted at a secondary hospital. Point-of-care blood glucose (BG) values, demographic data, medical history, glycaemic therapy and clinical characteristics were recorded. Dysglycaemia prevalence was calculated as proportions of BG-monitored days with at least one reading exceeding the cut points of 8 , 10 and $15 \mathrm{mmol} / \mathrm{L}$ for hyperglycaemia, and below the cut point of $4 \mathrm{mmol} / \mathrm{L}$ for hypoglycaemia.

RESULTS Among the 288 patients recruited, hyperglycaemia was highly prevalent $(90.3 \%, 81.3 \%$ and $47.6 \%$ for the respective cut points), while hypoglycaemia was the least prevalent (18.8\%). Dysglycaemic patients were more likely than normoglycaemic patients to have poorer glycated haemoglobin ( $\mathrm{HbA1c}$ ) levels $(8.4 \% \pm 2.6 \%$ vs. $7.3 \% \pm 1.9 \% ; p=0.002$ for $B G>10 \mathrm{mmol} / \mathrm{L})$ and longer lengths of stay $(10.1 \pm 8.2$ days vs. $6.8 \pm 4.7$ days; $p=0.007$ for $B G<4 \mathrm{mmol} / \mathrm{L})$. Hyperglycaemia was more prevalent in patients on more intensive treatment regimens, such as basal-bolus combination therapy and the use of both insulin and oral hypoglycaemic agents (100.0\% and $96.0 \%$, respectively; $p<0.001$ for BG $>10 \mathrm{mmol} / \mathrm{L})$. CONCLUSION Inpatient glycaemic control is suboptimal. Factors (e.g. type of treatment regimen, discipline and baseline $\mathrm{HbA1c}$ ) associated with greater prevalence of dysglycaemia should be given due consideration in patient management.

Keywords: diabetes mellitus, dysglycaemia, hospital, hyperglycaemia, inpatients

\section{INTRODUCTION}

Glycaemic control in the inpatient setting is an important indicator of the standards of hospital care.(1) This is especially fundamental in light of the rapidly growing evidence that poor glycaemic control is associated with poor clinical outcomes. ${ }^{(2)}$ Hyperglycaemia has been found to be a strong predictor of adverse clinical outcomes in patients with diabetes mellitus (DM) across a range of clinical situations. ${ }^{(3-8)}$ It has also been associated with in-hospital mortality. ${ }^{(4)}$ Other notable findings include a high overall mortality rate and high proportion of out-of-hospital deaths in hospitalised diabetic patients with a history of myocardial infarction. ${ }^{(6)}$ Likewise, there has been a significant increase in the short-term mortality, rate of surgical infection and number of postoperative complications in diabetic patients who undergo cardiac surgical procedures..$^{(7,8)}$

Despite the negative outcomes associated with hyperglycaemia, intervention to normalise glycaemia has yielded inconsistent results. Some studies have shown that intensive glucose control is not significantly beneficial in certain clinical situations ${ }^{(1,9)}$ and may result in greater risk of severe hypoglycaemia, ${ }^{(9)}$ which is linked to longer lengths of stay and higher mortality rates. ${ }^{(10,11)}$ Nevertheless, judicious control of glycaemia is still warranted:(1) a large number of studies clearly associate hyperglycaemia with numerous adverse outcomes and tight glycaemic control with beneficial outcomes.(1) A landmark study by van den Berghe et al demonstrated that tight glucose control, with target blood glucose (BG) levels of $80-110 \mathrm{mg} / \mathrm{dL}(4.4-6.1 \mathrm{mmol} / \mathrm{L})$, and the use of intravenous insulin in critically ill surgical patients led to reductions in acute renal failure, critical illness polyneuropathy, hospital mortality and bloodstream infection. ${ }^{(12)}$ In a follow-up study, tight glucose control in critically ill medical patients was found to have similar benefits, significantly reducing morbidity in patients with acute kidney injury, accelerating weaning from mechanical ventilation and reducing transfer time from intensive care units to general wards. ${ }^{(3)}$ The higher risk of hypoglycaemic events associated with tight glycaemic control can also be minimised via the relaxation of targets, improvement and standardisation of protocols, and careful implementation of these protocols. $^{(1)}$

Given the importance of judicious glycaemic control, it is important to identify glycaemic targets that are reasonable, achievable and safe. (1) Unfortunately, there is no internationally accepted definition of high-quality glycaemic control. Differing glycaemic targets published in established guidelines, from both the United States (US) and Europe, have made it more difficult to determine a standardised recommended glycaemic target. ${ }^{(1)} \mathrm{A}$ number of studies conducted in the US on the prevalence rates of dysglycaemia in the inpatient setting have found that the incidence of hyperglycaemia is high, while the incidence of hypoglycaemia is low. ${ }^{(13,14)}$ However, to the best of our knowledge, there has yet to be any published data on the prevalence rates of dysglycaemia in the local inpatient setting. Hence, the present study aimed to ascertain

${ }^{1}$ Department of Pharmacy, Faculty of Science, National University of Singapore, ${ }^{2}$ Specialist Outpatient Clinics, Department of Pharmacy, Singapore General Hospital, ${ }^{3}$ Department of Pharmacy, Khoo Teck Puat Hospital, ${ }^{4}$ Duke-NUS Graduate Medical School Singapore, Singapore

Correspondence: Mr Ong Kheng Yong, Pharmacist, Specialist Outpatient Clinics, Department of Pharmacy, Singapore General Hospital, Outram Road, Singapore 169608. ong. kheng.yong@sgh.com.sg 


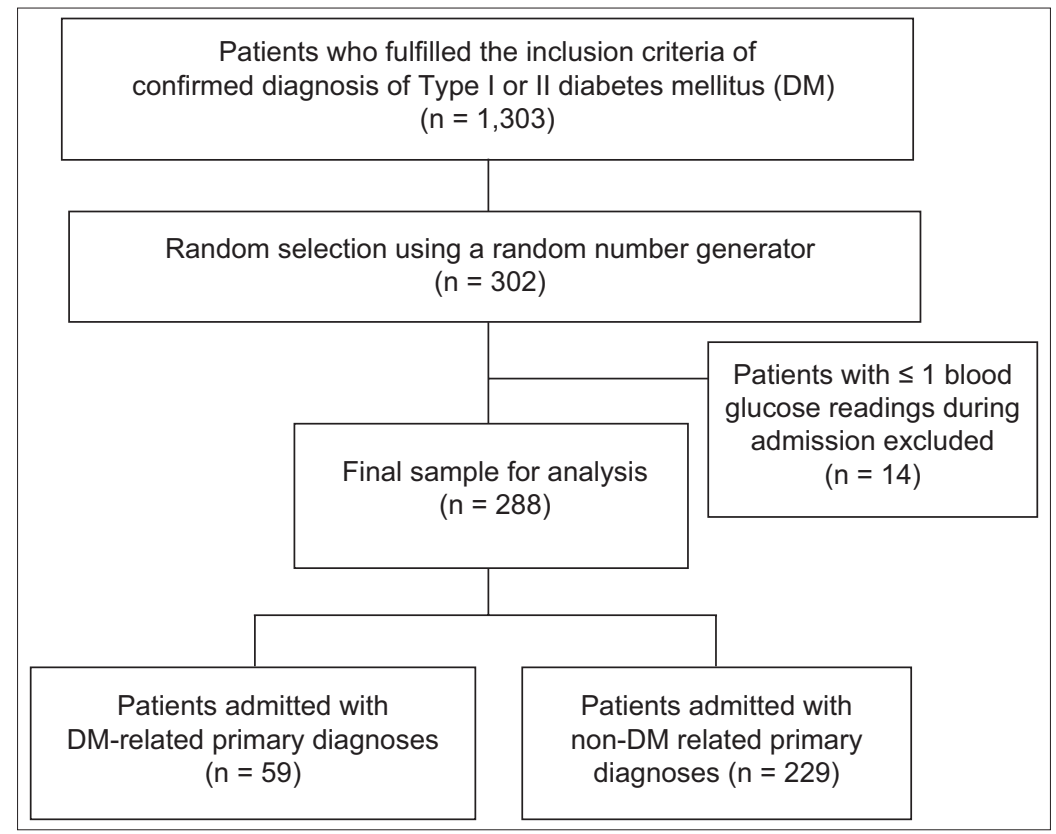

Fig. 1 Flowchart shows the patient recruitment process.

the incidence of dysglycaemia in hospitalised diabetic patients in Singapore, using cut points as defined in the American Association of Clinical Endocrinologists (AACE) and American Diabetes Association (ADA) Consensus Statement on inpatient glycaemic control $^{(1)}$ as well as cut points from the hospital's protocols, and to evaluate the quality of inpatient glycaemic care.

\section{METHODS}

This was a retrospective, observational, single-centre study conducted at Khoo Teck Puat Hospital, Singapore. Patients aged $\geq 18$ years who had a confirmed diagnosis of Type 1 or Type 2 DM were included in the study. Eligible patients were identified from a database of inpatient admissions from the hospital's Department of Clinical Services. Data on patients who were warded between June and November 2011 was retrieved and patients were randomly selected from this dataset using a random number generator. Patients with one reading or no testing of serum BG were excluded. Fig. 1 shows the patient recruitment process.

All BG values were recorded via point-of-care testing for preprandial BG monitoring. BG readings taken on the first day of hospitalisation were not recorded, as early BG control is affected by multiple variables that are beyond the control of the clinician and may not realistically reflect the effects of hospital care. ${ }^{(15)}$ The proportions of BG-monitored days with at least one $B G$ reading above the cut points of 8,10 and $15 \mathrm{mmol} / \mathrm{L}$, and below the cut point of $4 \mathrm{mmol} / \mathrm{L}$ were determined. The cut points of 8,10 and $15 \mathrm{mmol} / \mathrm{L}$ were selected to study the prevalence of hyperglycaemia. The cut point of $>8 \mathrm{mmol} / \mathrm{L}$ reflects an AACE/ADA recommendation (target premeal $\mathrm{BG}$ reading of $<7.8 \mathrm{mmol} / \mathrm{L}$ ), ${ }^{(1)}$ while the cut point of $>10 \mathrm{mmol} / \mathrm{L}$ reflects the target premeal $\mathrm{BG}$ reading of our hospital. A cut point of $>15 \mathrm{mmol} / \mathrm{L}$ was chosen as such BG levels are associated with detrimental vascular effects. ${ }^{(2)}$ The cut point of $<4 \mathrm{mmol} / \mathrm{L}$, which was selected to study the prevalence of hypoglycaemia, reflects the recommendation of the AACE/ADA to avoid $\mathrm{BG}$ readings of $<3.9 \mathrm{mmol} / \mathrm{L}$; this recommendation is similar to those in our hospital's guidelines.

Patient-day weighted mean (PDWM) values were calculated for further analysis. PDWM values correct for variations in the number of BG readings done per day by weighing all hospital days equally. ${ }^{(15)}$ Relevant demographic information, medical history, hospitalisation details, laboratory test results, and details on the use of insulin and oral hypoglycaemic agents (OHGAs) were also collected. Data was collected from case notes and the electronic clinical data monitoring system. The prevalence of dysglycaemia was compared between patients who were admitted for DM-related primary diagnoses and those who were admitted for non-DM-related primary diagnoses. Patients were also grouped into those who had at least one incidence of dysglycaemia and those who did not have any episodes of dysglycaemia (i.e. were normoglycaemic) during their length of stay. These two groups were compared at each cut point for differences across various patient variables. Statistical analysis was done using Predictive Analytics SoftWare for Windows version 18.0 (SPSS Inc, Chicago, IL, USA). Chi-square test was used to check for associations between discrete variables, while the analysis of variance and Student's $t$-test were used for continuous variables. A p-value $<0.05$ was considered statistically significant. The study protocol was approved by the Domain Specific Review Board of the National Healthcare Group and the need for individual informed consent was waived.

\section{RESULTS}

A total of 288 patients were recruited into the study (Fig. 1). Their baseline characteristics are summarised in Table I. Overall, these patients had similar demographic characteristics (i.e. age, gender and ethnicity). The most common non-DM-related primary diagnoses were respiratory system diseases (17.9\%).

In medical disciplines, a greater proportion of patients with a DM-related primary diagnosis were admitted than patients 
Table I. Baseline characteristics of the patients in the study.

\begin{tabular}{|c|c|c|c|c|}
\hline \multirow[t]{2}{*}{ Characteristic } & \multicolumn{3}{|c|}{ No. (\%) } & \multirow[t]{2}{*}{ p-value } \\
\hline & $\begin{array}{c}\text { Total } \\
(n=288)\end{array}$ & $\begin{array}{l}\text { DM-related primary } \\
\text { diagnosis }(n=59)\end{array}$ & $\begin{array}{l}\text { Non-DM-related primary } \\
\text { diagnosis }(n=229)\end{array}$ & \\
\hline Gender & & & & 0.130 \\
\hline Male & $128(44.4)$ & $21(35.6)$ & $107(46.7)$ & \\
\hline Female & $160(55.6)$ & $38(64.4)$ & $122(53.3)$ & \\
\hline Ethnicity & & & & 0.110 \\
\hline Chinese & $157(54.5)$ & $30(50.8)$ & $127(55.5)$ & \\
\hline Malay & $72(25.0)$ & $19(32.2)$ & $53(23.1)$ & \\
\hline Indian & $49(17.0)$ & $6(10.2)$ & $43(18.8)$ & \\
\hline Others & $10(3.5)$ & $4(6.8)$ & $6(2.6)$ & \\
\hline Discipline & & & & 0.003 \\
\hline Surgical & $46(16.0)$ & $2(3.4)$ & $44(19.2)$ & \\
\hline \multicolumn{5}{|l|}{ Primary diagnosis ${ }^{+}$} \\
\hline Respiratory system diseases & NA & NA & $41(17.9)$ & \\
\hline Circulatory system diseases & NA & NA & $25(10.9)$ & \\
\hline Genitourinary system diseases & NA & NA & $24(10.5)$ & \\
\hline Digestive system diseases & NA & NA & $20(8.7)$ & \\
\hline Endocrine/nutritional/metabolic diseases & NA & NA & $16(7.0)$ & \\
\hline HbA1c*,* (\%) & $8.1 \pm 2.5$ & $8.5 \pm 3.3$ & $8.1 \pm 2.2$ & 0.420 \\
\hline No. of comorbidities* & $2.9 \pm 1.6$ & $2.6 \pm 1.4$ & $3.0 \pm 1.7$ & 0.090 \\
\hline Inpatient treatment regimen & & & & 0.001 \\
\hline No treatment & $26(9.0)$ & $0(0)$ & $26(11.4)$ & \\
\hline Insulin only & $30(10.4)$ & $10(16.9)$ & $20(8.7)$ & \\
\hline Combination of insulin and OHGAs & $125(43.4)$ & $34(57.6)$ & $91(39.7)$ & \\
\hline Insulin regimen & & & & $<0.001$ \\
\hline No insulin & $133(46.2)$ & $15(25.4)$ & $118(51.5)$ & \\
\hline Basal insulin therapy only & $32(11.1)$ & $8(13.6)$ & $24(10.5)$ & \\
\hline Sliding scale insulin therapy only & $79(27.4)$ & $16(27.1)$ & $63(27.5)$ & \\
\hline Basal-bolus combination therapy & $44(15.3)$ & $20(33.9)$ & $24(10.5)$ & \\
\hline Length of stay* (day) & $7.4 \pm 5.6$ & $5.8 \pm 3.2$ & $7.8 \pm 6.0$ & 0.014 \\
\hline
\end{tabular}

* Data presented as mean \pm standard deviation. TOnly the top five categories of diseases are listed. $¥$ Only readings taken less than three months before or up to two months after the date of admission were considered. DM: diabetes mellitus; HbA1c: glycated haemoglobin; NA: not applicable; OHGAs: oral hypoglycaemic agents

with a non-DM-related primary diagnosis $(96.6 \%$ vs. $80.8 \%$, $\mathrm{p}=0.003)$. Overall, almost half $(46.2 \%)$ of the 288 patients did not receive any insulin. The combination regimen of insulin and OHGAs was the most commonly prescribed (43.4\%) treatment regimen. Among the patients who received insulin, the most common mode of insulin therapy was the sliding scale insulin therapy (27.4\%); basal insulin therapy $(11.1 \%)$ and basal-bolus combination therapy (15.3\%) were less common. However, among the patients with a DM-related primary diagnosis, the basal-bolus combination therapy was the most commonly used insulin regimen $(33.9 \%)$. It was more commonly used among the patients with a DM-related primary diagnosis than among the patients with a non-DM-related primary diagnosis $(33.9 \%$ vs. $10.5 \%, \mathrm{p}<0.001)$. Patients with non-DM-related primary diagnoses had longer lengths of stay $(7.8 \pm 6.0$ days vs. $5.8 \pm$ 3.2 days, $\mathrm{p}=0.014)$.
The prevalence rates of dysglycaemia are summarised in Table II. Almost all of the patients $(n=260,90.3 \%)$ had at least one episode of hyperglycaemia for BG $>8 \mathrm{mmol} / \mathrm{L}$. This number decreased to 234 (81.3\%) patients for BG > $10 \mathrm{mmol} / \mathrm{L}$ and 137 (47.6\%) patients for BG > $15 \mathrm{mmol} / \mathrm{L}$. Only 54 (18.8\%) patients experienced at least one episode of hypoglycaemia for BG $<4 \mathrm{mmol} / \mathrm{L}$. The prevalence of dysglycaemia was similar regardless of whether the patient was admitted for a DM-related or non-DM-related primary diagnosis.

The proportions of patient days during which dysglycaemia was present were noted for each cut point. At the cut point of $>8 \mathrm{mmol} / \mathrm{L}$, the mean proportion of patient days in which patients had hyperglycaemic episodes was $0.72 \pm 0.33(n=260)$. Even at the more stringent cut point of $\mathrm{BG}>10 \mathrm{mmol} / \mathrm{L}$, hyperglycaemic episodes were observed on more than half (i.e. $0.56 \pm 0.36$ ) of all the patient days $(n=234)$. The proportion of patient days with 
Table II. Prevalence of hyperglycaemia and hypoglycaemia among the patients in the study.

\begin{tabular}{|c|c|c|c|c|}
\hline \multirow[t]{2}{*}{ Variable } & \multicolumn{3}{|c|}{ No. (\%) } & \multirow[t]{2}{*}{ p-value ${ }^{+}$} \\
\hline & $\begin{array}{c}\text { Total } \\
(\mathrm{n}=\mathbf{2 8 8})\end{array}$ & $\begin{array}{l}\text { DM-related } \\
\text { primary diagnosis } \\
(n=59)\end{array}$ & $\begin{array}{l}\text { Non-DM-related } \\
\text { primary diagnosis } \\
(n=229)\end{array}$ & \\
\hline \multicolumn{5}{|c|}{ BG level indicating prevalence of hyperglycaemia (mmol/L)* } \\
\hline$>8$ & $260(90.3)$ & $57(96.6)$ & $203(88.6)$ & 0.070 \\
\hline$>10$ & 234 (81.3) & $55(93.2)$ & $179(78.2)$ & 0.050 \\
\hline$>15$ & $137(47.6)$ & $43(72.9)$ & $94(41.0)$ & $<0.001$ \\
\hline \multicolumn{5}{|c|}{ BG level indicating prevalence of hypoglycaemia (mmol/L)* } \\
\hline$<4$ & $54(18.8)$ & $8(13.6)$ & $46(20.1)$ & 0.250 \\
\hline
\end{tabular}

*At least one BG reading above or below cut point. ${ }^{\dagger}$ Chi-square test was used to compare discrete variables. BG: blood glucose; DM: diabetes mellitus

Table III. Comparison of the continuous variables of patients from the dysglycaemic and normoglycaemic groups $(\mathrm{n}=288)$.

\begin{tabular}{|c|c|c|c|c|c|c|c|c|c|}
\hline \multirow[t]{3}{*}{ Continuous variable } & \multicolumn{9}{|c|}{ Glycaemic cut point (mean \pm standard deviation) (mmol/L) } \\
\hline & \multicolumn{3}{|c|}{$>8$} & \multicolumn{3}{|c|}{$>10$} & \multicolumn{3}{|c|}{$<4$} \\
\hline & $\begin{array}{l}\text { Normal } \\
(n=28)\end{array}$ & $\begin{array}{l}\text { Hyperglycaemic } \\
(n=260)\end{array}$ & p-value* & $\begin{array}{l}\text { Normal } \\
(n=54)\end{array}$ & $\begin{array}{l}\text { Hyperglycaemic } \\
(n=234)\end{array}$ & p-value* & $\begin{array}{c}\text { Normal } \\
(n=234)\end{array}$ & $\begin{array}{l}\text { Hypoglycaemic } \\
(n=54)\end{array}$ & p-value* \\
\hline Age (yr) & $68.9 \pm 14.6$ & $66.4 \pm 13.4$ & 0.340 & $69.5 \pm 13.9$ & $66.0 \pm 13.4$ & 0.080 & $66.9 \pm 14.0$ & $65.5 \pm 11.7$ & 0.490 \\
\hline $\operatorname{HbA1c}(\%)(n=237)^{+}$ & $6.7 \pm 1.5$ & $8.3 \pm 2.5$ & $<0.001$ & $7.3 \pm 1.9$ & $8.4 \pm 2.6$ & 0.002 & $8.1 \pm 2.5$ & $8.7 \pm 2.5$ & 0.110 \\
\hline No. of comorbidities & $3.0 \pm 1.7$ & $2.9 \pm 1.6$ & 0.650 & $3.0 \pm 1.6$ & $2.9 \pm 1.7$ & 0.770 & $2.9 \pm 1.6$ & $3.1 \pm 1.6$ & 0.350 \\
\hline $\begin{array}{l}\text { Systolic blood } \\
\text { pressure }(\mathrm{mmHg})\end{array}$ & $135.5 \pm 22.6$ & $140.8 \pm 24.5$ & 0.270 & $140.1 \pm 23.1$ & $140.4 \pm 24.7$ & 0.940 & $141.3 \pm 24.5$ & $136.2 \pm 23.8$ & 0.170 \\
\hline $\begin{array}{l}\text { Body mass index } \\
\left(\mathrm{kg} / \mathrm{m}^{2}\right)(\mathrm{n}=253)^{\ddagger}\end{array}$ & $26.2 \pm 6.1$ & $24.5 \pm 5.1$ & 0.140 & $26.9 \pm 7.0$ & $24.1 \pm 4.6$ & 0.015 & $24.7 \pm 5.3$ & $23.9 \pm 4.7$ & 0.330 \\
\hline
\end{tabular}

*Analysis of variance and Student's $t$-test were used to compare between continuous variables. +51 patients did not have their HbA1c checked within three months of admission or discharge. $¥ 35$ patients did not have their weight measured. HbA1c: glycated haemoglobin

hypoglycaemia episodes $(\mathrm{BG}<4 \mathrm{mmol} / \mathrm{L})$ was notably smaller $(0.05 \pm 0.14)(n=54)$.

The patient characteristics of the dysglycaemic and normoglycaemic groups are summarised in Tables III and IV. Patients from the hyperglycaemic group tend to have higher glycated haemoglobin ( $\mathrm{HbA} 1 \mathrm{c})$ values than the patients from the normoglycaemic group $(8.3 \pm 2.5 \%$ vs. $6.7 \pm 1.5 \%, p<0.001$ for $\mathrm{BG}>8 \mathrm{mmol} / \mathrm{L} ; 8.4 \pm 2.6 \%$ vs. $7.3 \pm 1.9 \%, p=0.002$ for $\mathrm{BG}>10 \mathrm{mmol} / \mathrm{L})$. The length of stay was longer for patients from the hypoglycaemic group as compared to patients from the normoglycaemic group $(10.1 \pm 8.2$ days vs. $6.8 \pm 4.7$ days, $\mathrm{p}=0.007$ for $\mathrm{BG}<4 \mathrm{mmol} / \mathrm{L}$ ). The patients in the hyperglycaemic group also had lower body mass indices (BMIs) (24.1 \pm $4.6 \mathrm{~kg} / \mathrm{m}^{2}$ vs. $26.9 \pm 7.0 \mathrm{~kg} / \mathrm{m}^{2}, \mathrm{p}=0.015$ for BG $>10 \mathrm{mmol} / \mathrm{L}$ ). Surgical patients experienced more hypoglycaemia than medical patients $(34.8 \%$ vs. $15.7 \%, \mathrm{p}=0.002$ for $\mathrm{BG}<4 \mathrm{mmol} / \mathrm{L})$, and patients with $\mathrm{HbA} 1 \mathrm{c} \geq 7 \%$ experienced more hyperglycaemia than patients with $\mathrm{HbA} 1 \mathrm{c}<7 \%(95.0 \%$ vs. $86.5 \%, \mathrm{p}=0.020$, for $\mathrm{BG}>8 \mathrm{mmol} / \mathrm{L} ; 87.2 \%$ vs. $75.0 \%, \mathrm{p}=0.015$ for $\mathrm{BG}>10 \mathrm{mmol} / \mathrm{L}$ ). Glycaemic control also differed significantly among patients who were on different inpatient treatment regimens and among patients on different insulin regimens. Hyperglycaemia was more prevalent among the patients who were on more intensive treatment regimens, such as basal-bolus combination therapy, and combination treatment using insulin and OHGAs $(100.0 \%$ and $96.0 \%$, respectively; $\mathrm{p}<0.001$ for $\mathrm{BG}>10 \mathrm{mmol} / \mathrm{L}$ ). Patients who were administered dextrose infusions also experienced greater hyperglycaemia than those who did not receive any dextrose infusions (89.7\% vs. $78.1 \%, p=0.024$ for BG $>10 \mathrm{mmol} / \mathrm{L})$.

Further analysis was performed using PDWM values across the different patient variables to verify the aforementioned findings (Table V). PDWM values were higher among the medical patients than among the surgical patients $(10.0 \mathrm{mmol} / \mathrm{L}$ vs. $8.9 \mathrm{mmol} / \mathrm{L}$, $p=0.033)$. They were also higher among the patients with $\mathrm{HbA} 1 \mathrm{c} \geq 7 \%$ than among those with $\mathrm{HbA} 1 \mathrm{c}<7 \%(10.7 \mathrm{mmol} / \mathrm{L}$ vs. $8.6 \mathrm{mmol} / \mathrm{L}, \mathrm{p}<0.001)$. When the different inpatient treatment regimens were compared, we found that the PDWM values were higher among the patients who received OHGAs only $(11.8 \mathrm{mmol} / \mathrm{L})$ and among those who received a combination of insulin and OHGAs (11.2 mmol/L); the PDWM values among the patients who received only insulin $(8.3 \mathrm{mmol} / \mathrm{L})$ or no treatment $(7.0 \mathrm{mmol} / \mathrm{L})$ were lower $(\mathrm{p}<0.001)$. When the different insulin regimens were compared, the PDWM values were higher among the patients who received basal-bolus combination therapy (12.6 mmol/L) and among those who received sliding scale insulin therapy $(11.4 \mathrm{mmol} / \mathrm{L})$, as compared to those who received no insulin $(8.1 \mathrm{mmol} / \mathrm{L})$ and those who received basal insulin therapy only $(9.4 \mathrm{mmol} / \mathrm{L})(\mathrm{p}<0.001)$. PDWM values were also higher in those who received dextrose infusions as compared to those who did not $(11.1 \mathrm{mmol} / \mathrm{L}$ vs. $9.3 \mathrm{mmol} / \mathrm{L}, \mathrm{p}<0.001)$. As the findings based on PDWM values were concordant with the results that were based on prevalence rates, it is likely that these associations were not simply due to variations in the number of $\mathrm{BG}$ readings taken per day. 
Table IV. Comparison of the discrete variables of patients from the dysglycaemic and normoglycaemic groups $(\mathrm{n}=\mathbf{2 8 8})$.

\begin{tabular}{|c|c|c|c|c|c|c|c|c|c|}
\hline \multirow[t]{3}{*}{ Discrete variable } & \multicolumn{9}{|c|}{ Glycaemic cut point [no. (\%)] (mmol/L) } \\
\hline & \multicolumn{3}{|c|}{$>8$} & \multicolumn{3}{|c|}{$>10$} & \multicolumn{3}{|c|}{$<4$} \\
\hline & $\begin{array}{l}\text { Normal } \\
(n=28)\end{array}$ & $\begin{array}{l}\text { Hyperglycaemic } \\
(n=260)\end{array}$ & & $\begin{array}{l}\text { Normal } \\
(n=54)\end{array}$ & $\begin{array}{l}\text { Hyperglycaemic } \\
(n=234)\end{array}$ & p-value* & $\begin{array}{c}\text { Normal } \\
(n=234)\end{array}$ & $\begin{array}{l}\text { Hypoglycaemic } \\
(n=54)\end{array}$ & \\
\hline \multicolumn{10}{|l|}{ Demographic } \\
\hline Gender & & & 0.860 & & & 0.760 & & & 0.760 \\
\hline Female $(n=160)$ & $16(10.0)$ & $144(90.0)$ & & $31(19.4)$ & $129(80.6)$ & & $129(80.6)$ & $31(19.4)$ & \\
\hline Ethnicity & & & 0.270 & & & 0.090 & & & 0.100 \\
\hline Chinese $(n=157)$ & $18(11.5)$ & $139(88.5)$ & & $35(22.3)$ & $122(77.7)$ & & $133(84.7)$ & $24(15.3)$ & \\
\hline Non-Chinese $(n=131)$ & $10(7.6)$ & $121(92.4)$ & & $19(14.5)$ & $112(85.5)$ & & $101(77.1)$ & $30(22.9)$ & \\
\hline \multicolumn{10}{|l|}{ Admission } \\
\hline Discipline & & & 0.790 & & & 0.880 & & & 0.002 \\
\hline Surgical $(n=46)$ & $5(10.9)$ & $41(89.1)$ & & $9(19.6)$ & $37(80.4)$ & & $30(65.2)$ & $16(34.8)$ & \\
\hline ICU admission & & & 0.390 & & & 0.210 & & & 0.540 \\
\hline Yes $(n=17)$ & $0(0)$ & $17(100.0)$ & & $1(5.9)$ & $16(94.1)$ & & $13(76.5)$ & $4(23.5)$ & \\
\hline No $(n=271)$ & $28(10.3)$ & $243(89.7)$ & & $53(19.6)$ & $218(80.4)$ & & $221(81.5)$ & $50(18.5)$ & \\
\hline Baseline $\mathrm{HbA} 1 \mathrm{c}^{\dagger}$ & & & 0.020 & & & 0.015 & & & 0.110 \\
\hline$H b A 1 c<7 \%(n=96)$ & $13(13.5)$ & $83(86.5)$ & & $24(25.0)$ & $72(75.0)$ & & $84(87.5)$ & $12(12.5)$ & \\
\hline$H b A 1 c \geq 7 \%(n=141)$ & $7(5.0)$ & $134(95.0)$ & & $18(12.8)$ & $123(87.2)$ & & $112(79.4)$ & $29(20.6)$ & \\
\hline $\begin{array}{l}\text { Inpatient treatment } \\
\text { regimen }\end{array}$ & & & $\mathrm{NA}^{*}$ & & & $<0.001$ & & & 0.070 \\
\hline No treatment $(n=26)$ & $9(34.6)$ & $17(65.4)$ & & $14(53.8)$ & $12(46.2)$ & & $26(100.0)$ & $0(0)$ & \\
\hline Insulin only $(n=30)$ & $0(0)$ & $30(100.0)$ & & $2(6.7)$ & $28(93.3)$ & & $25(83.3)$ & $5(16.7)$ & \\
\hline OHGAs only $(n=107)$ & $18(16.8)$ & $89(83.2)$ & & $33(30.8)$ & $74(69.2)$ & & $85(79.4)$ & $22(20.6)$ & \\
\hline Insulin regimen & & & $\mathrm{NA}^{*}$ & & & $<0.001$ & & & 0.100 \\
\hline No insulin $(n=133)$ & $27(20.3)$ & $106(79.7)$ & & $47(35.3)$ & $86(64.7)$ & & $111(83.5)$ & $22(16.5)$ & \\
\hline $\begin{array}{l}\text { Basal insulin therapy } \\
(n=32)\end{array}$ & $0(0)$ & $32(100.0)$ & & $4(12.5)$ & $28(87.5)$ & & $21(65.6)$ & $11(34.4)$ & \\
\hline $\begin{array}{l}\text { Sliding scale insulin } \\
\text { therapy }(n=79)\end{array}$ & $1(1.3)$ & $78(98.7)$ & & $3(3.8)$ & $76(96.2)$ & & $67(84.8)$ & $12(15.2)$ & \\
\hline $\begin{array}{l}\text { Basal-bolus combination } \\
\text { therapy }(n=44)\end{array}$ & $0(0)$ & $44(100.0)$ & & $0(0)$ & $44(100.0)$ & & $35(79.5)$ & $9(20.5)$ & \\
\hline \multicolumn{10}{|l|}{ Factor affecting BG control } \\
\hline Corticosteroid use & & & 0.630 & & & 0.150 & & & 0.310 \\
\hline Yes $(n=14)$ & $2(14.3)$ & $12(85.7)$ & & $5(35.7)$ & $9(64.3)$ & & $10(71.4)$ & $4(28.6)$ & \\
\hline No $(n=274)$ & $26(9.5)$ & $248(90.5)$ & & 49 (17.9) & $225(82.1)$ & & $224(81.8)$ & $50(18.2)$ & \\
\hline $\begin{array}{l}\text { Use of dextrose } \\
\text { ( } 5 \% \text { or } 10 \% \text { ) infusion }\end{array}$ & & & 0.250 & & & 0.024 & & & 0.900 \\
\hline Yes $(n=78)$ & $5(6.4)$ & $73(93.6)$ & & $8(10.3)$ & $70(89.7)$ & & $63(80.8)$ & $15(19.2)$ & \\
\hline No $(n=210)$ & $23(11.0)$ & $187(89.0)$ & & $46(21.9)$ & $164(78.1)$ & & $171(81.4)$ & $39(18.6)$ & \\
\hline
\end{tabular}

* Chi-square test was used to compare between discrete variables. tOnly readings taken less than three months before or up to two months after the date of admission were considered. $¥$ Not applicable as > $20 \%$ of cells had an expected count of < 5 . BG: blood glucose; HbA1c: glycated haemoglobin; ICU: intensive care unit; NA: not applicable; OHGAs: oral hypoglycaemic agents

\section{DISCUSSION}

To the best of our knowledge, while studies examining the prevalence of dysglycaemia have been done in the US, no such study has been conducted in an Asian population. The development of DM in Asian populations differs from that in US populations due to a multitude of factors, including a higher prevalence of the normal-weight 'metabolically obese' phenotype, a higher intake of refined carbohydrates (e.g. white rice) and different lifestyle factors (e.g. differences in smoking, alcohol use and physical activity). ${ }^{(16)}$ Moreover, Singapore has a unique multiethnic population consisting of Chinese, Malay, Indian and Eurasian ethnicities.

When the prevalence of hyperglycaemia in the present study (which was observed in hospitalised patients) was compared with 
Table V. Comparison of PDWM values $(n=288)$.

\begin{tabular}{|c|c|c|}
\hline \multirow[t]{2}{*}{ Discrete variable } & \multicolumn{2}{|c|}{ PDWM } \\
\hline & Mean \pm SD & p-value* \\
\hline \multicolumn{3}{|l|}{ Demographic } \\
\hline Gender & & 0.070 \\
\hline Male & $10.2 \pm 3.7$ & \\
\hline Female & $9.5 \pm 2.9$ & \\
\hline Ethnicity & & 0.320 \\
\hline Chinese & $9.6 \pm 3.5$ & \\
\hline Non-Chinese & $9.9 \pm 3.1$ & \\
\hline \multicolumn{3}{|l|}{ Admission characteristic } \\
\hline Discipline & & 0.033 \\
\hline Medical & $10.0 \pm 3.3$ & \\
\hline Surgical & $8.9 \pm 2.8$ & \\
\hline ICU admission during stay & & 0.060 \\
\hline Yes & $11.3 \pm 2.9$ & \\
\hline No & $9.7 \pm 3.3$ & \\
\hline Overall glucose control & & $<0.001$ \\
\hline$H b A 1 c<7 \%$ & $8.6 \pm 2.3$ & \\
\hline$H b A 1 c \geq 7 \%$ & $10.7 \pm 3.1$ & \\
\hline Inpatient treatment regimen & & $<0.001$ \\
\hline No treatment & $7.0 \pm 1.4$ & \\
\hline Insulin only & $8.3 \pm 2.1$ & \\
\hline OHGAs only & $11.8 \pm 5.0$ & \\
\hline Combination of insulin and OHGAs & $11.2 \pm 2.9$ & \\
\hline Insulin regimen & & $<0.001$ \\
\hline No insulin & $8.1 \pm 2.0$ & \\
\hline Basal insulin therapy only & $9.4 \pm 2.3$ & \\
\hline Sliding scale insulin therapy only & $11.4 \pm 2.8$ & \\
\hline Basal-bolus combination therapy & $12.6 \pm 4.4$ & \\
\hline \multicolumn{3}{|l|}{ Factor affecting blood glucose control } \\
\hline Corticosteroid use & & 0.960 \\
\hline Yes & $9.8 \pm 3.1$ & \\
\hline No & $9.8 \pm 3.3$ & \\
\hline Use of dextrose ( $5 \%$ or $10 \%$ ) infusion & & $<0.001$ \\
\hline Yes & $11.1 \pm 3.9$ & \\
\hline No & $9.3 \pm 2.9$ & \\
\hline
\end{tabular}

* Chi-square test was used to compare between discrete variables, and the analysis of variance and Student's $t$-test were used for continuous variables. HbA1c: glycated haemoglobin; ICU: intensive care unit; OHGAs: oral hypoglycaemic agents; PDWM: patient-day weighted mean; SD: standard deviation

similar studies conducted in the US, we found that the prevalence rates of the present study were higher at similar cut points. Two US studies by Cook et al and Wexler et al, which defined hyperglycaemia as BG values $>180 \mathrm{mg} / \mathrm{dL}(>10.0 \mathrm{mmol} / \mathrm{L})$ and $>200 \mathrm{mg} / \mathrm{dL}(>11.1 \mathrm{mmol} / \mathrm{L})$, respectively, found that the prevalence rates among their study cohorts were $46.4 \%$ and $77.0 \%$, respectively. ${ }^{(13,14)}$ In the present study, for the cut point of $>10 \mathrm{mmol} / \mathrm{L}$, we found a prevalence rate of $81.3 \%$, which was higher than those in the two US studies. For hypoglycaemia, a prevalence rate of $18.8 \%$ was found in the present study (for BG $<4 \mathrm{mmol} / \mathrm{L}$ ), while the two aforementioned US studies reported rates of $21.3 \%$ and $12.0 \%$ for the cut points of $<70 \mathrm{mg} / \mathrm{dL}$ $(<3.89 \mathrm{mmol} / \mathrm{L})$ and $<60 \mathrm{mg} / \mathrm{dL}(<3.33 \mathrm{mmol} / \mathrm{L})$, respectively.
It should be noted, however, that the results of these studies may not be directly comparable due to differences in study design and factors such as geographical region. ${ }^{(13)}$ For example, Wexler et al may have underestimated prevalence rates in their study cohort as they only collected data on the two days before and after the most extreme BG values of each patient. ${ }^{(14)}$ Regardless, the high prevalence of hyperglycaemia found in the present study suggests that greater attention should be paid to glycaemic control in Asian populations.

In the present study, patients with a DM-related primary diagnosis seemed to be managed differently from those with a non-DM-related primary diagnosis (Table I). Differences in terms of the discipline (i.e. medical or surgical) patients are assigned to are likely due to the fact that, in the absence of any complications requiring surgical intervention, patients with DM-related primary diagnoses are automatically placed in the medical discipline. Differences in inpatient treatment regimen and insulin regimen may indicate that patients are managed differently according to their diagnoses. However, despite these differences, the prevalence of dysglycaemia did not differ significantly between the patients with a DM-related primary diagnosis and those with a non-DM-related primary diagnosis. As the type of diagnosis and its corresponding associations with the prevalence of dysglycaemia have not been investigated, further research with larger sample sizes may be warranted.

Patient factors associated with dysglycaemia were examined in the present study. Interestingly, patients in the hyperglycaemic group were found to have lower BMls than patients in the normoglycaemic group $\left(24.5 \mathrm{~kg} / \mathrm{m}^{2}\right.$ vs. $26.2 \mathrm{~kg} / \mathrm{m}^{2}$ for BG $>8 \mathrm{mmol} / \mathrm{L}$ ) (Table III). This finding is unexpected as obesity has been shown to be associated with poor glycaemic control due to greater insulin resistance. ${ }^{(17)}$ However, it is noteworthy that this relationship has only been examined and established in the context of long term glycaemic control. It is also noteworthy that patients in our study sample had relatively healthy BMIs. More research is needed before any relationship can be drawn between $\mathrm{BMI}$ and inpatient glycaemic control.

In the present study, a larger proportion of surgical patients experienced hypoglycaemia as compared to medical patients, which was concordant with the lower mean PDWM values found in the surgical patients (Tables IV \& V). This finding may be due to the practice of more intensive glycaemic control among surgical patients. Many studies have demonstrated an association between hyperglycaemia and suboptimal perioperative outcomes. ${ }^{(7,8,12,18)}$ However, the present study may indicate that while intensive glycaemic control is important in surgical patients, those who undergo intensive glycaemic control could be at greater risk of hypoglycaemia. Physicians should be aware of this and ensure that such patients are monitored closely.

Significant differences were found between patients with $\mathrm{HbA} 1 \mathrm{c}<7 \%$ and those with $\mathrm{HbA} 1 \mathrm{c} \geq 7 \%$ at both hyperglycaemic cut points. A greater proportion of patients with $\mathrm{HbA} 1 \mathrm{c} \geq 7 \%$ experienced hyperglycaemia as compared to those with $\mathrm{HbA} 1 \mathrm{c}$ $<7 \%$. Similarly, higher PDWM values are associated with patients with $\mathrm{HbA} 1 \mathrm{c} \geq 7 \%$. This suggests that patients admitted 
with $\mathrm{HbA} 1 \mathrm{c} \geq 7 \%$ are more likely to take a longer time to reach glycaemic targets and that more intensive glycaemic control may be needed for these patients. In turn, it may be prudent to obtain each patient's most recent $\mathrm{HbA} 1 \mathrm{c}$ reading to determine the intensity of glycaemic control required during inpatient admission. This practice is recommended by the ADA in their position statement. ${ }^{(17)}$ In the present study, although recent $\mathrm{HbA} 1 \mathrm{c}$ values were either obtained or $\mathrm{HbA} 1 \mathrm{c}$ value was tested during admission for the large majority of patients $(82.3 \%)$, glycaemic control in our study cohort remained less than optimal. While it is unclear whether knowledge of these patients' $\mathrm{HbA} 1 \mathrm{c}$ values had influenced the intensity of glycaemic control, recent evidence suggests that $\mathrm{HbA} 1 \mathrm{c}$ may not be as useful in guiding glycaemic control in Asian patients. ${ }^{(19)}$ It has been shown that $\mathrm{HbA} 1 \mathrm{c}$ values tend to be higher in South Asians than white Europeans, independent of the factors affecting glycaemic control. ${ }^{(19)}$ In addition, a more recent prospective cohort study showed that South Asians with poorly controlled DM are less likely to achieve controlled $\mathrm{HbA} 1 \mathrm{c}$ and respond less favourably to treatment in terms of $\mathrm{HbA} 1 \mathrm{c}$ levels. ${ }^{(20)}$ While it is unclear whether these findings can be extrapolated to inpatients in an acute care setting, it suggests that $\mathrm{HbA} 1 \mathrm{c}$ alone is not a good indicator of the intensity of treatment required and that clinicians should utilise other indicators (e.g. BG levels) to guide glycaemic management.

At the hyperglycaemic cut point of $>10 \mathrm{mmol} / \mathrm{L}(\mathrm{p}<0.001)$, significant differences in the prevalence of dysglycaemia were found among patients who were on different inpatient treatment regimens and among patients on different insulin regimens (Table III). A greater proportion of patients on intensive treatment and insulin regimens experienced hyperglycaemia, which was concordant with the higher PDWM values found among the patients on the more intensive treatment and insulin regimens (Tables III \& V). PDWM values were highest among the patients who received the combination of insulin and OHGAs, and among the patients who received basal-bolus combination therapy. It is especially noteworthy that the patients who received no hypoglycaemic therapy had the lowest PDWM values (7 mmol/L). This could be due to their stable glycaemic control prior to and during hospital admission, which negated the need for hypoglycaemic therapy. One limitation of this observational study was the inability to draw 'cause and effect' conclusions. Although a large proportion of patients who were hyperglycaemic or had higher PDWM values were associated with more intensive treatment regimens, these relationships cannot be interpreted as cause and effect. They may simply indicate that patients with higher BG levels tend to require more intensive treatment.

It is noteworthy that the treatment options chosen for patients in the present study (for achieving glycaemic control) appear to differ from the recommendations found in the consensus statement by the AACE/ADA. ${ }^{(1)}$ In the study, insulin was used on only slightly more than half of the patients ( $n=155,53.8 \%$ ), despite recommendations in favour of insulin therapy as the preferred method for achieving glycaemic control in the inpatient setting. The consensus statement also advises against the use of the sliding scale insulin therapy as the sole regimen due to its ineffectiveness. Instead, it recommends the use of basal-bolus combination therapy. ${ }^{(1)}$ In the present study, however, sliding scale insulin therapy was the most commonly used insulin regimen $(27.4 \%)$; only a minority $(15.3 \%)$ received basal-bolus combination therapy. Although the AACE/ADA consensus statement does not recommend the use of OHGAs during hospitalisation, it states that OHGAs may be appropriate for use in selected stable patients who are expected to consume meals at regular intervals. This may explain why $37.2 \%$ of our patients received $\mathrm{OHGAs}$ alone for their treatment. Given the significant differences found in the prevalence of dysglycaemia among patients on different treatment regimens and among patients on different insulin regimens, further research in the form of prospective studies may be warranted to examine whether greater adherence to the AACE/ADA guidelines would lead to a lower prevalence of dysglycaemia.

In the present study, we also found an association between the use of dextrose infusions and hyperglycaemia (Table V). Patients who received dextrose infusions had significantly higher PDWM values than those who did not. Close monitoring of patients who are receiving dextrose infusions is advisable to enable prompt correction of hyperglycaemia. In terms of outcomes, hypoglycaemia was associated with longer lengths of stay in the present study. This finding is consistent with the results of other published studies. ${ }^{(10,11)}$ While the authors of those studies did not provide evidence to explain this association, they hypothesised that hypoglycaemia could have affected the length of stay directly, by causing events such as falls and seizures, or indirectly, by resulting in the need to adjust the patients' treatment plans and/ or delays to tests and procedures. ${ }^{(10)}$

The present study had several limitations. The main limitation is that it was observational in nature. Hence, we were not able to establish cause-effect relationships for the variables associated with dysglycaemia. The retrospective nature of the present study also limits us from assessing the reasons underlying how dysglycaemia is managed in our institution. Prospective studies are needed to investigate whether the factors that we found to be associated with a greater prevalence of dysglycaemia are truly causative. There is also no consensus regarding how glycaemic control should be measured and reported in hospitals. ${ }^{(15)}$ Therefore, it is important to develop guidelines for inpatient glycaemic control reporting that take into consideration correlations to clinical importance and hospital outcomes. This would allow standards of glycaemic control to be assessed more objectively and extended to other institutions.

Despite the limitations of the present study, its findings are useful as they provide a first glimpse of inpatient glycaemic control in an Asian population, specifically Singapore's multiethnic population. To the best of our knowledge, no such data has been published to date. The data obtained from the present study can help pave the way for future research.

Overall, there was a high prevalence of hyperglycaemia, especially at the lowest cut point of $>8 \mathrm{mmol} / \mathrm{L}$, which is the goal advocated in the AACE/ADA consensus statement. This highlights that it was difficult to achieve good glycaemic control in the inpatient setting using the hospital's current practice. 
Given the well-documented adverse effects of hyperglycaemia and the relatively low incidence of hypoglycaemia, it may be more prudent to manage hyperglycaemia more aggressively than to adjust current glycaemic targets. We recommend that glycaemic goals be individualised according to individual patient profiles (e.g. for surgical patients, who may be more predisposed to hypoglycaemia, caution and close monitoring should be in place to avoid hypoglycaemia). In general, intensive glycaemic control is recommended as long as a hypoglycaemia management protocol is adopted and implemented..$^{(17)}$

Further research and increased hospital participation in data collection and reporting are needed to facilitate the development of best practices and improve inpatient glycaemic control. Until there is more evidence to justify changes to the current practices in glycaemic control, it is imperative that healthcare providers exercise due clinical judgment, in combination with careful ongoing assessment of the patient's clinical status, in the day-today management of DM patients. ${ }^{(17)}$

To conclude, the prevalence of hyperglycaemia among the Asian patients in our study was high, while the prevalence of hypoglycaemia was relatively low. This suggests that the current quality of inpatient glycaemic control is suboptimal. Several factors, such as the type and intensity of treatment, patient discipline and baseline $\mathrm{HbA} 1 \mathrm{c}$, are associated with a greater prevalence of dysglycaemia. Due regard should be given to these factors in the management of diabetic patients in Asian populations. Future research should address the relationship between these factors and dysglycaemia.

\section{REFERENCES}

1. Moghissi ES, Korytkowski MT, DiNardo M, et al; American Association of Clinical Endocrinologists; American Diabetes Association. American Association of Clinical Endocrinologists and American Diabetes Association consensus statement on inpatient glycaemic control. Diabetes Care 2009; 32:1119-31.

2. Clement S, Braithwaite SS, Magee MF, et al; American Diabetes Association Diabetes in Hospitals Writing Committee. Management of diabetes and hyperglycemia in hospitals. Diabetes Care 2004; 27:553-91.

3. Van den Berghe G, Wilmer A, Hermans G, et al. Intensive insulin therapy in the medical ICU. N Engl J Med 2006; 354:449-61.
4. Umpierrez GE, Isaacs SD, Bazargan N, et al. Hyperglycemia: an independent marker of in-hospital mortality in patients with undiagnosed diabetes. J Clin Endocrinol Metab 2002; 87:978-82.

5. Malmberg K, Rydén L, Wedel H, et al; DIGAMI 2 Investigators. Intense metabolic control by means of insulin in patients with diabetes mellitus and acute myocardial infarction (DIGAMI 2): effects on mortality and morbidity. Eur Heart J 2005; 26:650-61.

6. Miettinen $\mathrm{H}$, Lehto $\mathrm{S}$, Salomaa $\mathrm{V}$, et al. Impact of diabetes on mortality after the first myocardial infarction. The FINMONICA Myocardial Infarction Register Study Group. Diabetes Care 1998; 21:69-75.

7. Carson JL, Scholz PM, Chen AY, et al. Diabetes mellitus increases shortterm mortality and morbidity in patients undergoing coronary artery bypass graft surgery. J Am Coll Cardiol 2002; 40:418-23.

8. Latham R, Lancaster AD, Covington JF, Pirolo JS, Thomas CS Jr. The association of diabetes and glucose control with surgical-site infections among cardiothoracic surgery patients. Infect Control Hosp Epidemiol 2001; 22:607-12.

9. Fowler MJ. Inpatient Diabetes Management. Clin Diabetes 2009; 27:119-22.

10. Turchin A, Matheny ME, Shubina M, et al. Hypoglycemia and clinical outcomes in patients with diabetes hospitalized in the general ward. Diabetes Care 2009; 32:1153-7.

11. Curkendall SM, Natoli JL, Alexander CM, et al. Economic and clinical impact of inpatient diabetic hypoglycemia. Endocr Pract 2009; 15:302-12.

12. van den Berghe $G$, Wouters $P$, Weekers $F$, et al. Intensive insulin therapy in critically ill patients. N Engl J Med 2001; 345:1359-67.

13. Cook CB, Kongable GL, Potter DJ, et al. Inpatient glucose control: a glycaemic survey of 126 U.S. hospitals. J Hosp Med 2009; 4:E7-E14.

14. Wexler DJ, Meigs JB, Cagliero E, Nathan DM, Grant RW. Prevalence of hyper- and hypoglycemia among inpatients with diabetes: a national survey of 44 U.S. hospitals. Diabetes Care 2007; 30:367-9.

15. Schnipper JL, Magee M, Larsen K, Inzucchi SE, Maynard G; Society of Hospital Medicine Glycaemic Control Task Force. Society of Hospital Medicine Glycaemic Control Task Force summary: practical recommendations for assessing the impact of glycaemic control efforts. J Hosp Med 2008; 3(5 Suppl):66-75.

16. Hu FB. Globalization of diabetes: the role of diet, lifestyle, and genes. Diabetes Care 2011; 34:1249-57.

17. American Diabetes Association. Standards of medical care in diabetes--2012. Diabetes Care 2012; 35 Suppl 1:S11-63.

18. Rizvi AA, Chillag SA, Chillag KJ. Perioperative management of diabetes and hyperglycemia in patients undergoing orthopaedic surgery. J Am Acad Orthop Surg 2010; 18:426-35.

19. Mostafa SA, Davies MJ, Webb DR, et al. Independent effect of ethnicity on glycemia in South Asians and white Europeans. Diabetes Care 2012; 35:1746-8.

20. James GD, Baker P, Badrick E, et al. Type 2 diabetes: a cohort study of treatment, ethnic and social group influences on glycated haemoglobin. BMJ Open 2012; 2. pii: e001477. 